This is the post-peer reviewed final draft version of the following article: Heeks, R. "Health information systems: failure, success and improvisation", International Journal of Medical Informatics, 75(2), 125-137, 2006, which has been published in final form at: http://www.sciencedirect.com/science/article/pii/S1386505605001255

\title{
Health Information Systems: Failure,
}

\section{Success and Improvisation}

\author{
Richard Heeks \\ IDPM \\ University of Manchester \\ Manchester M13 9QH \\ England \\ Tel: $+44-1612752800$ \\ Fax: +44-161 2738829 \\ Email: richard.heeks@manchester.ac.uk
}

Keywords: Information Systems; Systems Analysis; Evaluation; Organisational Change;

Risk Management 
Summary Points:

- Despite complexities of definition and a weak evidence base, the best estimate is that HIS failure is a significant problem.

- The design - reality gap model provides a conceptual basis on which to understand and address HIS success and failure.

- This model can be used as an evaluation tool showing how large design — reality gaps underpin HIS failure and small gaps underpin success.

- The model can be used as a risk management tool that identifies major sources of risk in an HIS project, and that suggests appropriate mitigating actions.

- The model validates an emergent and improvising approach to HIS implementation that differs from traditional, planned methodologies. 


\title{
Health Information Systems: Failure,
}

\section{Success and Improvisation}

\begin{abstract}
Background and purpose: The generalised assumption of health information systems (HIS) success is questioned by a few commentators in the medical informatics field. They point to widespread HIS failure. The purpose of this paper was therefore to develop a better conceptual foundation for, and practical guidance on, health information systems failure (and success).

Methods: Literature and case analysis plus pilot testing of developed model.

Results: Defining HIS failure and success is complex, and the current evidence base on HIS success and failure rates was found to be weak. Nonetheless, the best current estimate is that HIS failure is an important problem. The paper therefore derives and explains the "design—reality gap" conceptual model. This is shown to be robust in explaining multiple cases of HIS success and failure, yet provides a contingency that encompasses the differences which exist in different HIS contexts. The design—reality gap model is piloted to demonstrate its value as a tool for risk assessment and mitigation on HIS projects. It also throws into question traditional, structured development methodologies, highlighting the importance of emergent change and improvisation in HIS.
\end{abstract}


Conclusions: The design — reality gap model can be used to address the problem of HIS failure, both as a post hoc evaluative tool and as a pre hoc risk assessment and mitigation tool. It also validates a set of methods, techniques, roles and competencies needed to support the dynamic improvisations that are found to underpin cases of HIS success. 


\section{Introduction}

The medical informatics literature presents, by and large, a picture of successful health information systems (HIS): the modal form of journal article and conference paper is an implementation case study that is adjudged to be a success. There is a negative bias against publication of failures found in healthcare literature more broadly and in medical informatics literature specifically $[1,2]$. Hence, just a small handful of writings strike a discordant note, claiming there to be significant numbers of HIS failures.

This paper - aligning itself with the minority literature - sets out to investigate HIS failure. Its initial task will be to review the nature and extent of this failure. If, as seems likely, there are significant problems with significant numbers of information technology (IT)-based systems in healthcare, this creates a major gap between the positive potential for informatics to contribute to the work of healthcare organisations and a more negative reality. This, in turn, means that increasingly large sums of money are being invested in new health information systems but that a substantial proportion of this will go to waste on unimplemented or ineffective systems.

Dissatisfied with the analyses of HIS failure offered to date, this paper develops a new model that may offer a better understanding of that failure (and, equally, of success). This, in turn, can highlight interventions that may help to reduce the risk of systems failure. 


\section{Defining and Estimating HIS Failure and Success}

Any discussion of HIS success and failure must begin with a definition of its terms.

Such an attempt runs into some immediate difficulties that this paper, while recognising, cannot completely resolve. The first difficulty is the subjectivity of evaluation: viewed from different perspectives, one person's failure may be another's success $[3,4]$.

This problem can be partly addressed through a three-way categorisation of HIS initiatives:

- The total failure of an initiative never implemented or in which a new system is implemented but immediately abandoned. Such an outcome can be defined relatively objectively.

- The partial failure of an initiative in which major goals are unattained or in which there are significant undesirable outcomes. In some cases - for example, where only a subset of initially-stated objectives has been achieved - the notion of partial failure may be relatively straightforward. Other partial failures, though, are more difficult to identify because identification grapples with the issue of subjectivity. This requires evaluation to ask: "Whose goals are unattained?" and "For whom are the outcomes undesirable?"

- The success of an initiative in which most stakeholder groups attain their major goals and do not experience significant undesirable outcomes. Again, there will be subjectivity in identifying such outcomes. 
Given this categorisation, one could then review literature data in order to produce estimates of success and failure.

In attempting this, one runs into a further difficulty. Despite the fact that evaluation as a topic offers a higher profile within the medical informatics literature than within the broader information systems (IS) literature, the base of evaluative case study data from which one could estimate success and failure rates is weak: "most of the available literature refers only to pilot projects and short-term outcomes, and in many cases the efficacy of the application was being considered, rather than its effectiveness" [5]. These weaknesses can be teased out:

- Timing: reporting pilots and prototypes rather than fully-operational systems is problematic in itself. It also highlights the problem of timing in the determination of success and failure, where today's HIS success may be tomorrow's HIS failure, and vice versa [6]. This issue remains largely unrecognised within the medical informatics literature, where data is almost universally cross-sectional rather than longitudinal. It is thus blind to the sustainability failure of HIS that succeed initially but are then abandoned after a relatively short period of time. It is also blind to the abandoned failure that is then revived at some later stage. Yet both exist in practice: a point discussed later in this paper.

- Objectivity of categorisation: the definitions of partial failure and of success are only operationalisable where evaluation methods recognise subjectivity, and recognise and interact with multiple stakeholder groups. Yet most reported case studies take a positivist approach to evaluation that assumes an objectivity to success and failure [7]. 
- Objectivity of data: more contentiously, one may reflect that many HIS paper authors are the developers of the system they seek to report due, in part, to the strong historical practice-orientation of academic groups within medical informatics [8]. They therefore lack the distancing and independence from the object of study that are norms of methodological rigour in referent medical or information systems disciplines.

Given that case study material forms a poor basis for estimation, we must turn instead to the few instances of cross-case data. Some of this data relates to specific types of application, for example:

- Clinical decision making systems: "Currently prevalent systems ... have high failure rates" [9].

- Computer-assisted learning in medicine: "many of these programmes failed" [10].

- Mobile computing healthcare systems: "Studies evaluating prototypes have revealed that acceptance of such tools was rather low" [11].

- Shared decision making (SDM) systems: "Studies examining the adoption of SDM tools to support patients in treatment or screening decisions have reported clinicians' reluctance to use such tools" [12].

Some data relates to particular countries and health systems, for example:

- "people within the NHS [UK National Health Service] and without appear to believe that this organization has experienced relatively high rates of IS failure" [13].

- "Doctors in Norwegian hospitals reported a low level of use of all electronic medical records systems" [14].

Other data is generic: 
- "70 percent of the systems either fail or do not provide end-user satisfaction" [15].

- "there are many more failure stories to tell than there are success stories" [16].

- "Even in today's health care organizations, more than 25 years after the inception of the field, truly successful HIS stories are not common. On the other hand, failures are highly visible, widespread, and costly" [17].

- "Most healthcare informatics professionals today have experienced or are familiar with one or more system failures. Many healthcare institutions have consumed huge amounts of money and frustrated countless people in unsuccessful IS efforts." [18].

Unfortunately, in almost all cases, the source of this data is either one or two individual case studies, or uncited. The Anderson figure [15] appears to derive from a survey, though the source is not entirely clear. One is left with estimates that appear more like assertions, or generalisations from personal or very limited experience.

To conclude, then, both the conceptualisation and the evidence base for HIS success and failure are weak. Both need strengthening. All one can say is that the data is at least suggestive that success and failure rates for HIS are not significantly out of line with rates reported from general IS surveys. Leaving aside the challenging issue of success and failure's evolutionary nature, these latter report that something like one-fifth to one quarter of IS projects fall into the total failure category; something like one-third to three-fifths fall into the partial failure category; and only a minority fall into the success category. 


\section{Understanding HIS Failure and Success}

The best estimate, from an admittedly poor evidence base, is that most HIS fail in some way. In this section, we seek to understand why this should be.

Interest in HIS failure is not new but analysis of the limited past literature suggests it has tended to fall into one of two related traps. One trap relates to generalisability. Some studies are overly-specific; focusing on a single case study of failure from which it is hard to legitimately generalise conclusions (e.g. $[19,20])$. Other studies are overlygeneric, providing prescriptive "cookbook" guidance that is intended to apply in all circumstances (e.g. [18]). In both cases, the studies fail to recognise the situationspecific factors that determine success and failure for each particular HIS [21].

The other trap relates to conceptualisation. Some HIS studies provide a useful practical technique but provide no clear conceptual model as a foundation (thus limiting the confidence with which one can generalise from the initial study) (e.g. [22]). Others provide strong conceptual foundations but can offer limited practical guidance (e.g. [23]).

Such a characterisation is echoed in analyses of the broader literature on IS failure and risk, which adds one further trap [24]. This is the contrast between IS studies that are static, concerned solely with factors underlying success/failure, and those which are solely dynamic, concerned with the process of IS implementation that ends in success or failure. 
We thus have three pairs of Scylla and Charybdis that - not without difficulty - must be steered between. Dealing with these in reverse order, this paper takes a route that attempts to encompass both static factors and dynamic process; that provides a conceptual foundation to its practical guidance; and that draws from multiple case studies in order to offer some confidence of generalisability, but also draws centrally on the notion of contingency in order to deliver a model that can be shaped to the differing circumstances of differing health information systems.

Inherent within most ideas of contingency is the idea of fit or congruence: of mismatch and match between and within factors and of the need to change in order to adapt systems so that there is more match than mismatch. There are different variants of contingency models but one main concept has been that of fit between an organisational system - an information system, a management system, etc. - and its environment [25]. Within the information systems literature, there is variation in the environmental factor or factors that an information system is supposed to fit with. One important strand has been work looking at the fit between technology and the task it is intended to support $[26,27]$. Another has been writings on fit between IS and organisational strategy [28, 29].

There are two problems, though, with these earlier contingent approaches. First, they tend to be narrow: picking on just one or two factors despite the fact that IS success and failure are seen to be multi-factoral [24]. Second, in seeking to match an IS to its environment, they produce a logical challenge: if, for example, a health information 
system were to exactly match its environment, it would not change that environment in any way. Yet the formal purpose of HIS is to support and bring about organisational change in order to improve the functioning of healthcare organisations. There must therefore be some degree of change that an HIS introduces.

On the other hand, if a health information system tries to change too much this brings with it a risk of failure and, the more you change, the greater this risk [16]. In the much-cited London Ambulance Service case, for example, failure arose because "the speed and depth of change were simply too aggressive for the circumstances." [30].

\section{Dimensions of Change: Design-Reality Gaps}

From the previous section, we see that the amount of change between "where we are now" and "where the HIS wants to get us" is central to health information system success and failure.

The former will be represented by the current realities of the particular healthcare context. The latter will be represented by the model of conceptions and assumptions that have been inscribed into the new HIS design. Putting this a little more precisely, then, the model proposed here would state that success and failure depend on the size of gap that exists between "current realities" and "design conceptions of the HIS". More plainly, this can be referred to as the "design—reality gap". 
In practice, because of subjective expectations about the future and subjective perceptions of reality, it could be argued that every individual HIS stakeholder has their own design and their own version of reality. Among these myriad design — reality gaps, we must necessarily simplify the model. Drawing on a thread within the IS failure literature [3,31], the two key homogenised stakeholders in the model presented here will be the designers who create the dominant HIS design, and the users who populate the local reality.

These groups are especially valuable to an understanding of failure given their dislocation, in both psychological and even physical terms, as part of the HIS implementation process. However, this simplification does impose limits; for example, limiting subjective partial failures to a consideration of the objectives of these two stakeholder groups alone.

What could be relevant dimensions of this 'design — reality gap' between the designers' dominant design and the local actuality of the users? The dimensions could be built up in a number of ways: theoretically on the basis of literature; descriptively on the basis of a straightforward delineation of components of an information system; and analytically on the basis of case studies. An amalgam of all three approaches is presented here.

In all, as noted above, the design is a representation of an intentional future. It is a world-in-miniature that contains elements that have been inscribed either explicitly or implicitly. These elements include: 
- Components from the designers' own context: health information system design is a situated action - an action "taken in the context of particular, concrete circumstances" [32]. This action draws elements of that context into the design:

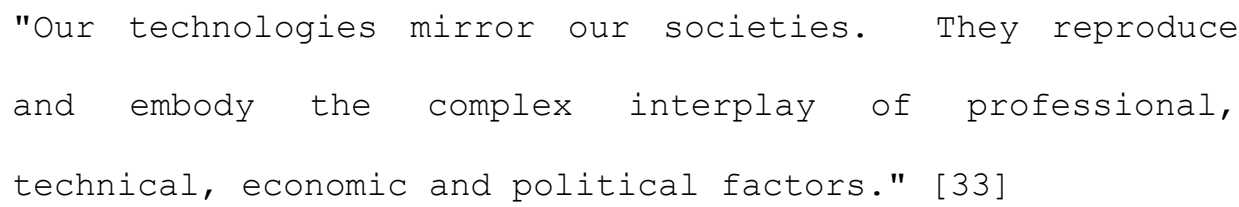

Designers themselves are part of and shaped by that context, and so their own cultural values, objectives, etc. will be found inscribed in the design [34,35].

- Conceived assumptions about the situation of the user: this includes assumptions about the users' activities, skills, culture and objectives, and assumptions about the user organisation's structure, hardware and software infrastructure, etc. [32,36,37].

This literature therefore suggested a need to encompass issues of objectives and values, activities, human skills, organisational structure, and technical infrastructure. This was combined with more descriptive material on key factors that underlie IS implementation such as data, financial resources, and their coordination through managerial systems (e.g. $[24,38])$. Together, these suggested seven dimensions of relevance to designreality gaps: information (data stores, data flows, etc.); technology (both hardware and software); processes (the activities of users and others); objectives and values (the key dimension, through which factors such as culture and politics are manifest); staffing and skills (both the quantitative and qualitative aspects of competencies); management systems and structures; and other resources (particularly time and money). These 'ITPOSMO' dimensions are summarised in Figure 1. 

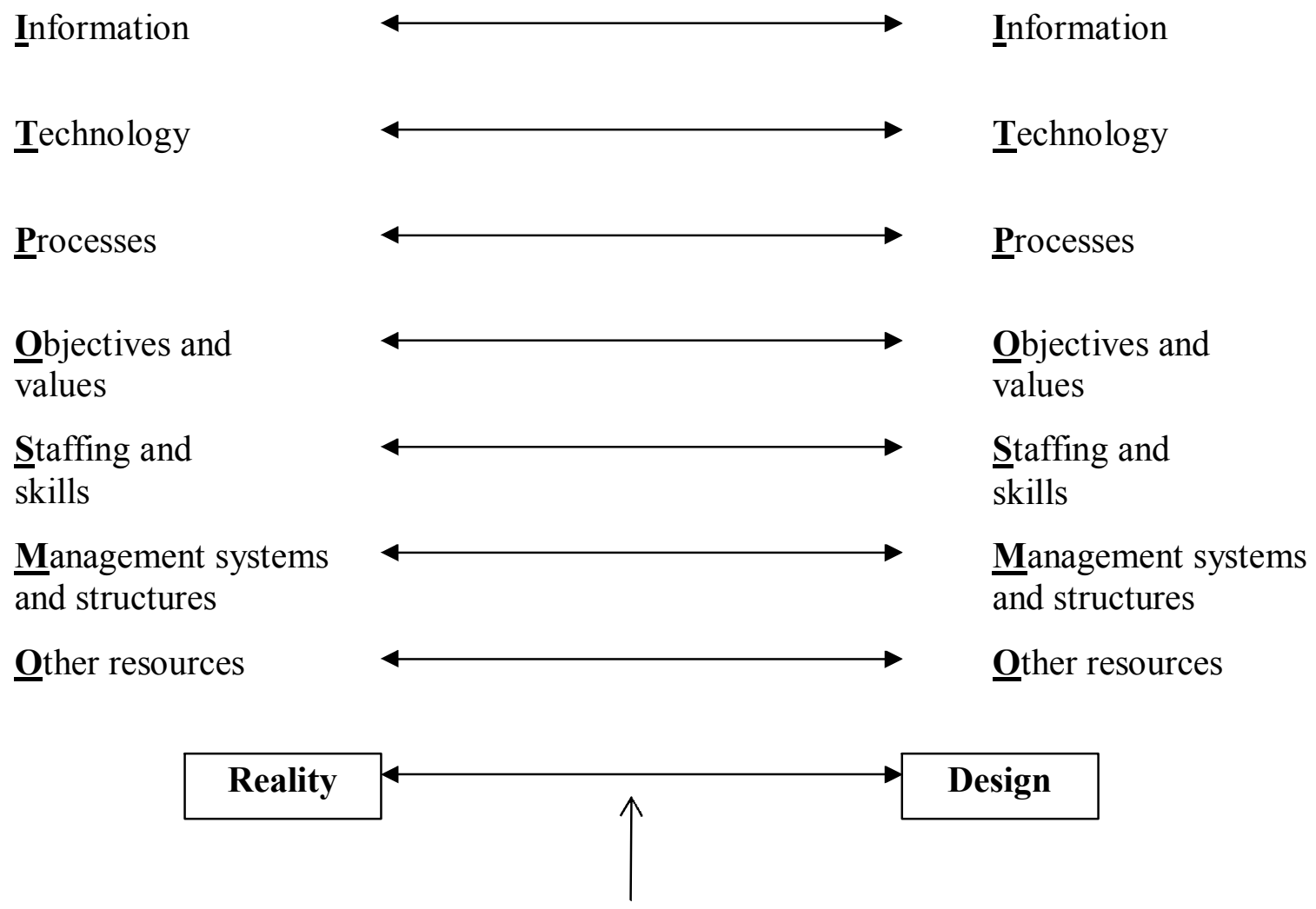

Gap

Fig. 1. The ITPOSMO dimensions of health information system design—reality gaps.

These seven dimensions, which were presented in an earlier paper [39], have now been tested through analysis of information systems case studies from the healthcare sector. Some of these cases are summarised in the current paper while others are presented elsewhere $[40,41,42]$. This analysis has confirmed that these seven dimensions are necessary and sufficient to provide an understanding of design —reality gaps. For each of the seven dimensions, the gap between design and reality can be assessed and rated (e.g. low, medium, high). Overall ratings will give a sense of mismatch between design and reality and, hence, a view of the likelihood of success or failure. 
Just one example will be given here, using the design — reality gap model to analyse a UK hospital's attempt to introduce an expert system for computerised coloscopy [43]. The system design was conceived mainly by technical staff and there were significant design — reality gaps along a number of the ITPOSMO dimensions:

- Information: the expert system was designed to produce a set of statistical information on coloscopy, but it emerged that there was no significant demand for this information from potential users. There was thus a large gap between the system's information design and the information realities of existing hospital practice.

- Technology: the expert system required a relatively powerful technological infrastructure, which differed markedly from the hospital's current technological realities

- Processes: the expert system was designed to automate many of the currently human decision-making processes around coloscopy. This created a significant gap between the new processes conceived within the system design and the current process reality.

- Objectives and values: because of the process automation, the system's design did not match well with the objectives and values of medical staff who feared automation and who believed that human inputs remained critical. Nor did the expert system's objectives match well with the priorities of senior hospital managers, leading to their providing little, if any, support for the project.

- Staffing and skills: the expert system was relatively difficult to use and there was thus a significant gap between the requirements of its design and the reality of availability and expertise of hospital staff. 
- Management and structures: there was little design—reality gap along this dimension.

- Other resources: the expert system was both time-consuming and costly to operate.

This created a serious gap between the system's design requirements and the realities of resource availability within the hospital.

Overall, there was too great a gap between the design conceptions of the expert system and the realities of the hospital use context into which it was being introduced. The result was that the pilot project was abandoned, as could be expected because of its outsize design—reality gap.

\section{Archetypes of Health Information System Failure}

Design - reality gaps can arise in any situation but we can highlight some archetypes of large gaps that make HIS failure more likely.

\section{Hard-Soft Gaps}

A number of differing "hard" rationalities dominate the healthcare system, typically associated with particular stakeholder groups $[44,45]$. Not surprisingly, these rationalities may themselves then be inscribed into the design of health information systems. Different rationalities will be inscribed depending on which stakeholder group's worldview dominates the HIS design process. Three archetypal examples will be provided here $[4,6,46,47]$ : 
- Technical rationality. Technology is typically conceived as an objective and rational entity, not as something that incorporates particular cultural and political values. When information technology is seen to play a central role in HIS, those information systems are therefore themselves likely to be conceived according to an objective and rational model. This may occur particularly, though not exclusively, where IT professionals dominate the design process, allowing a technology-based worldview to dominate design inscriptions.

- Managerial rationality. Health managers have their own objectives but are also the conduit for the objectives of external stakeholder groups such as governments or shareholders. Such objectives can relate to legal or bureaucratic rationalities but they frequently relate to money. Like technology, money is typically conceived as an objective and rational entity. When financial information is seen to play a central role in HIS, those information systems are therefore themselves likely to be conceived according to an objective and rational model. This may occur particularly, though not exclusively, where healthcare managers dominate the design process, allowing a finance-based worldview to dominate design inscriptions.

- Medical rationality. Although it deals with people, medicine is also frequently conceived in an objective and rational manner where diseases and injuries, not patients, are the focal entity. When medical information is seen to play a central role in HIS, those information systems are therefore themselves likely to be conceived according to an objective and rational model. This may occur particularly, though not exclusively, where clinicians dominate the design process, allowing a medicinebased worldview to dominate design inscriptions. 
The hard technical or managerial or medical worldview inscribed into HIS design may find a match with user realities, particularly if users are drawn from the same stakeholder group as the designers (for example, where clinicians design a system for use by clinicians). However, there are many other possibilities. It may be that "rationalities collide"; for example, where a system inscribed with a financially-rational design conflicts with a user reality based on medical rationality. It can also be the case that a hard design conflicts with the "softer" behavioural realities of the user group. This may occur where users adhere to more informal, "muddling through" decision processes [48]. It may also occur where users adhere to the softer "rationality of caring" that incorporates more emotional, informal and adaptive elements into its worldview [49]. In either case, there will be a large gap between the HIS's formal, rational design conceptions and the more informal, behavioural realities of healthcare practitioners. In all these latter examples, there will be an increased likelihood of HIS failure.

This can be illustrated with the example of a clinical information system that failed in one UK hospital. The failure arose when the information system, based by its designers on a formal, technically-rational model of hospital functioning, was introduced into a much "messier" informal reality, leading to "a clear mismatch between the formal models [within the IS] and the perceptions of system users who inevitably reflect a more informal and pragmatic approach to their own organizational realities." [50]. There was a mismatch particularly along the process, objectives, and management systems and structures dimensions of the ITPOSMO model. The "prescriptive and utterly inflexible" information system that resulted was of little use to healthcare practitioners. 


\section{Design-Implementation Context Gaps}

The previous section gave what are often intra-organisational examples of situations in which the context for HIS design is not the same as the context for implementation and use. There can also be inter-organisational examples of this problem.

\section{Public-Private Sector Gaps}

Taking the specific illustrative example of hospitals, significant differences exist between public/non-profit and private/for-profit hospitals along all seven ITPOSMO dimensions [51]. For instance, in terms of technology, public hospitals tend to have a more limited and older technological infrastructure than that found in private hospitals. In terms of staffing and skills, public hospitals tend to have fewer nursing staff and fewer technology-related staff than private hospitals.

Given these differences, information systems or techniques developed for private sector hospital use can easily be based on designs that do not match public sector hospital realities. They will therefore be more prone to failure if introduced into a public sector hospital.

We will illustrate this not with an individual information system but with an approach to the development of multiple information systems: strategic information systems planning (SISP). SISP was designed within and for the private sector, based on design assumptions about unitary organisational objectives, apolitical decision making, and the presence of skilled support for implementation that do not apply in many public sector 
healthcare organisations [40]. This design—reality mismatch can make traditional SISP risky and/or impractical in the public sector. This was epitomised in the UK public sector by cancellation of the Wessex Regional Health Authority's Regional Information Systems Plan, causing an estimated $£ 20$ million (c.US\$33m) to be wasted [30].

\section{Country Gaps}

Taking the specific illustrative example of differences between developing and industrialised countries, significant differences exist between these nations along all seven ITPOSMO dimensions [52]. For instance, in terms of processes, work processes tend to be more contingent in developing countries because of the more politicised and inconstant environment. In terms of management systems and structures, developing country healthcare organisations tend to be more hierarchical and more centralised than their industrialised country counterparts.

Perhaps even more than with the public — private gaps, it is important to recognise these as stereotypes that mask great diversity both within and between developing countries. Nonetheless, HIS designed for use in an industrialised country can easily be based on design conceptions that do not match user realities in a developing country. They will therefore be more prone to failure if introduced into that particular developing country context.

For example, in the Philippines, an aid-funded project to introduce a public health services information system was designed according to a Western model that assumed the presence of skilled programmers, skilled project managers, a sound technological 
infrastructure, and a need for information outputs like those used in an American health care organisation [53]. In reality, none of these was present in the Philippine context and the information system failed.

\section{Addressing HIS Failure I: Design—Reality Gaps as a Risk}

\section{Assessment Tool}

Thus far, the design - reality gap model has been shown to work as a post hoc tool; providing a fairly simple contingent framework for explaining why health information systems succeed or fail. We now turn to look at its potential as a pre hoc tool; providing guidance on ways to assess and mitigate the risks of failure in a health informatics project. This can be done in two ways. In this section, a straightforward micro-level, technique-focused approach is used; seeing the model as a technique for use within a traditional HIS development lifecycle. In the next section, a more mesolevel, methodology-focused approach is discussed.

If the design — reality concept is to be applied as a tool for risk management within the development lifecycle, the first step is assessment: predicting the likelihood of success and failure by identifying design—reality gaps.

The design — reality gap model can be used as a risk assessment tool for individual managers and consultants working on HIS projects. However, it has actually been piloted with small groups of managers and IT professionals through a facilitated 
workshop that brings together key stakeholders involved with a project. This has been done at the University of Manchester working with mid-career professionals on inservice training. The workshop focus is the design — reality gap model, with each dimension converted into one or more rating scale questions. For example, the information dimension question can ask: "What is the gap between the information assumptions/requirements of the new HIS design, and the information currently in use in reality in the healthcare organisation?".

Following initial presentations about the project, participants then discuss and score these scales either openly or anonymously. Discussion and scoring takes place in rounds as an iterative process, with the facilitator identifying and working to resolve the main differences of opinion. The intended output from the workshop is a map of the key design — reality gaps (i.e. risks) that may undermine the HIS project.

A quick and dirty approach to the rating scales has been to allocate one $0-10$ scale per dimension. A rather more time-consuming approach would be to allocate several rating scale questions to each dimension and to allow at least some of those scales to be developed by workshop participants, according to individual project context. Starting points for these "sub-dimension" questions, which also help explain the focus of each dimension, are as follows:

- Information: information quantity, quality, and flow; informal information.

- Technology: computer hardware, and software; telecommunications; other healthcare technology. 
- Processes: information-handling; decision-making; actions/transactions; other healthcare processes; informal processes.

- Objectives and values: objectives of medical staff, non-medical staff, and other stakeholders; values of medical staff, non-medical staff, and other stakeholders.

- Staffing and skills: staff numbers; technical skills; management skills; healthcare skills; other skills; knowledge.

- Management systems and structures: management systems; management structures; informal systems and structures.

- Other resources: initial investment; ongoing expenditure; time; other healthcare resources.

Once the sub-dimension question scales have been produced, they would be group- and iteratively-rated as described above.

The main role for this process is through involvement of project stakeholders. However, it can also find a role as the focal point for the peer review and oversight actions that are introduced into HIS projects in attempts to lower failure rates.

Identification of risks in a health informatics project is valuable but practitioners will likely be more concerned about methods for avoiding or reducing risks; in other words, the risk assessment techniques just identified must be placed alongside risk mitigation techniques in an overall risk management process. Specific design-reality gaps, identified by a workshop or other process, can be reduced (i.e. risks can be mitigated) by changing the project design to make it closer to current reality, or by changing current reality to make it closer to the project design. 
Selected techniques will, of course, depend on which dimension(s) the gap occurs. For example, one can take the fairly straightforward issue of a financial gap along the "other resources" dimension. This gap could be reduced by scaling-down the project remit and thereby reducing cost (design change). Or it could be reduced through seeking additional funding sources that increase the supply of available finance (reality change).

An example of design change can be seen, in relation to processes and management systems dimensions, when an original design option for a new hospital IS in Guatemala was to re-engineer administrative processes to make them more efficient [54]. In reality, hospital directors supported current procedures and wanted controls to remain in place to ensure corruption was held in check. The design was therefore amended to ensure that these current work processes and their related systems were supported by the new application, thereby closing the gap between design and reality.

\section{Addressing HIS Failure II: Design—Reality Gaps as a Dynamic, Improvising Development Approach}

The preceding section showed how the design—reality gap model can be used as one technique for risk management within a conventional HIS development methodology. The model can also be used, though, to question such methodologies. 
For example, many HIS methodologies take a techno-centric approach, denying any role for the human and social components of an information system $[20,55,56]$. A review of design — reality's ITPOSMO dimensions is a reminder of the essentially sociotechnical nature of health information systems and, hence, of a need to adopt sociotechnical methodologies, such as Multiview, when introducing such systems. However, that is all this is - a reminder - since the importance of socio-technical approaches is well recognised already within at least a fraction of the medical informatics community (see, for example, [46,57,58]).

Rather than focus on the dimensions - which are little more than a checklist - the critique offered here draws from the central notion of design and reality. In some ways, the archetypes of HIS failure presented above take a rather static view: a cross-sectional perspective of large mismatches between design and user reality that mean a high risk of failure. The limitations of a cross-sectional view of failure were noted above and, likewise, neither design nor reality should be seen as static; they are dynamic. They both change constantly throughout all phases of an HIS project as, therefore, do design—reality gaps.

In this way, we can explain the dynamic and evolutionary nature of HIS success and failure. For example, we can explain the sustainability failures described at the start of the paper in terms of a growth of design — reality gaps during implementation and operation. Typical examples arise from reality changes:

- along the other resources dimension when initial funding for an HIS project comes to an end; 
- along the staffing and skills dimension when key technical staff are redeployed; or

- along the objectives and values dimension when senior-level champions move on.

Likewise, we should not interpret HIS success as simply being an instantaneous closure of design — reality gaps. Instead, closure must be seen as a process that is not only dynamic - occurring over time - but which also needs to be sustained continuously throughout the life of an HIS project.

In conceptual terms, this represents a shift from the sense of planned change associated with the static view underlying the first half of this paper to a sense of emergent change that is associated with local improvisations [59]. These emergent changes can be envisaged as continuous reciprocating improvisations between design and reality that, if success is to be achieved, will seek accommodation and adaptation between design and reality sufficient to achieve workable and sustainable closure $[60,61]$.

The growing recognition of the importance of improvisation has led some to decry planning and control in HIS projects as a myth [16] or even to reject the whole notion of method [62]. This may be too extreme a counter-reaction but we can certainly conclude that - alongside planned method - we need a greater emphasis in HIS on emergent change and on improvisation. The remainder of this paper looks at what could be done to create an enabling context that would assist the design—-reality closure improvisations that appear to be an important part of HIS project success. We consider three aspects: methods, techniques, and roles and competencies. 


\section{Methods}

HIS projects delivered via the "big bang" approach of instant cut-over to the complete new system provide no legitimate space for improvised design—reality gap closure. Users are left to achieve this closure via work-arounds or through post hoc requests for programming changes. A better alternative that enables - even legitimises improvisation is one that takes an iterative approach. Iteration is built on two components: structure and process.

In structural terms, HIS projects need to be delivered in steps. This can be done through modularity (supporting one healthcare function at a time) and incrementalism (providing stepped levels of support for healthcare functions) within HIS projects (see Figure 2). It can also be done by pilot-and-scale-up (supporting one location first and then gradually rolling-out an HIS to other locations). 


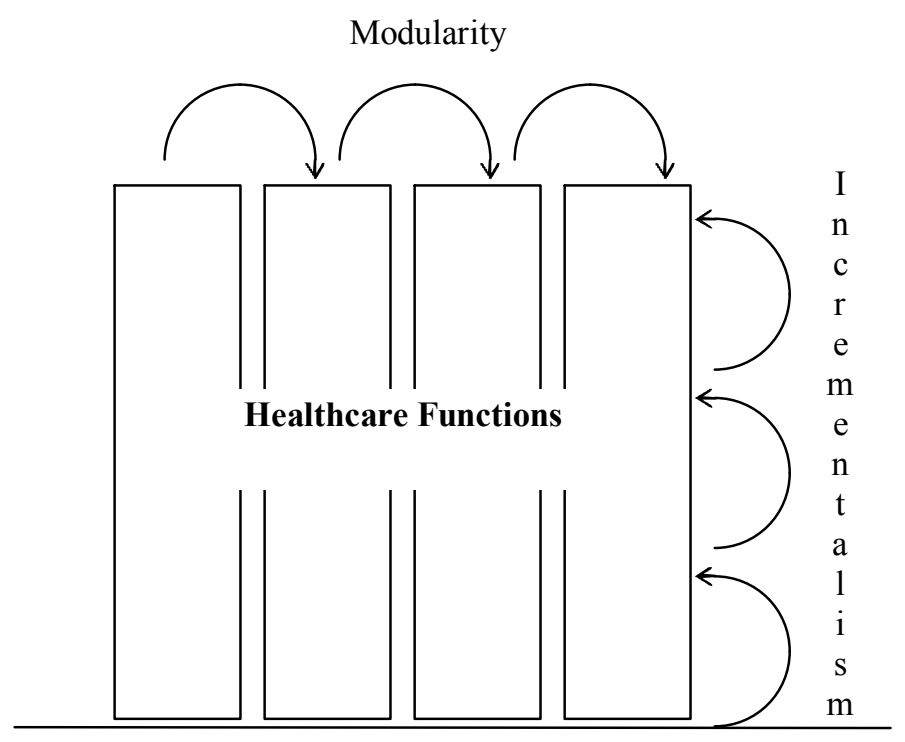

Fig. 2. Modularity and incrementalism for healthcare projects.

These steps help by reducing the extent of difference between design and reality - i.e. the extent of change - that must be endured at any one time. However, the steps are also valuable because they provide the framework within which one can site a process of learning; of reflection on the current state of design and current state of reality, and of improvised action to address these if large gaps are emergent. Hence, the association of stepped approaches with successful delivery of health information systems [63,64].

In this paper, we have focused on developer design and user reality. If there is to be improvisation and closure between these two, the overall method adopted must allow for two-way communication between users and developers. This cannot happen in traditional top-down IS development methods, where communication between these two groups is seen, at best, as a one-way and partial process. It can only happen properly if a participative method is followed; one that allows users to better understand the design, 
and designers to better understand user reality. This explains why, where such methods have been used, they have typically formed an important element in successful HIS implementation (e.g. $[20,65])$ and their absence has been associated with HIS failure (e.g. [66]).

\section{Techniques}

Even if a stepped and participative method provides the context, improvised designreality gap closures can only take place if those involved have the right tools to hand. One basket of these will be the type of ethnographic tools that provide a proper understanding of current realities. These will include observational techniques such as self- or third party observation, and use of soft systems tools such as rich pictures that provide a graphical and in-depth means of recording reality, including the informal and socio-political components of reality [67].

These tools put designers in touch with user reality. Equally important are techniques like prototyping that put users in touch with design. Of itself, prototyping just provides a better sense for all stakeholders of what the design — reality gaps are. However, prototyping is much more than this; it is a mechanism that legitimates the process of improvisation - of design — reality gap closure - within HIS development. Hence, its association with successful HIS $[68,69]$.

There are signs of such techniques becoming more of a toolkit that combines improved IT-based diagramming techniques with flexible computer-aided software engineering 
tools to create a "responsive IT infrastructure" for healthcare organisations that can support iterative, prototyping-based methods [64]. In other words, IT innovations can increasingly enable dynamic gap-closing approaches to HIS implementation.

\section{Roles and Competencies}

Appropriate methods and techniques provide the basis for gap-closing improvisations, but the ability of stakeholders to enact such improvisations will depend partly on their roles and competencies. In particular there is a need for what are recognised in the broader IS field as "hybrids" [70]. The term "hybrid" is rarely used in the medical informatics literature and yet they are continuously visible in case analyses of successful HIS that discuss roles, in descriptions of key actors who are "bridgers" or "spanners" or who "blend" or "intertwine" [18,71,72].

The central importance of the hybrid is that they understand the world of the developer and the world of the user. They can therefore play a key role in the improvisation of both design and reality, and help to improve success rates. They may do this by taking direct action themselves to alter HIS design or to alter current user realities. Or they may do this by enabling others, particularly through a "translation" or "interpretation" role that helps communication [73].

The actual nature of hybrids seems to vary in terms of the worlds that they combine or bridge. They are always "technical and something" but that "something" varies. It can 
be health management [15]; it can be clinical practice [72]; it can be nursing care [74]. In all cases, though, the hybrid is seen as a keystone role for HIS success.

In some cases, hybrids seem to just emerge, though mainly they start outside the technical domain, and pick up IT competencies [72]. It seems much rarer for someone working in health IT to develop the non-IT competencies needed for a hybrid role. However, leaving the emergence of such key actors to chance seems foolish. Hence, the growing attempts to use education and training to formally create hybrids (e.g. [57]).

The ultimate expression of the hybrid is someone who combines both developer and user within one individual: as found in the case of end-user development. By placing design directly into the hands of those who understand user reality, end-user development greatly facilitates both design_-reality gap closure overall and continuing improvisations: any changes in reality are readily detected and readily responded to through HIS re-design. Thus end-user development has been associated with successful HIS development (e.g. [75,76]).

However, this defines success in user terms. As Berg [16] notes, enabling improvisation in this way can lead to a proliferation of different system customisations. While giving individual users what they want, this may create a sub-optimal solution for the healthcare group or organisation. We end, then, with a reminder that the parameters of planning may be useful in some situations to create the boundaries "within which user involvement can emerge and can express itself." [ibid.]. 


\section{Conclusion}

There is no panacea for avoiding failure in health informatics projects. If there were, it would have been discovered long ago. One must therefore be guarded in any claims made for the design — reality gap model.

The model is non-judgemental in its assessments: it does not distinguish between a current health reality that is chaotic and needs changing, and a reality that is effective in delivering health services and should be preserved. Partly related to this, the model's strength as a project technique seems to lie in risk assessment. In other words, it is good at identifying constraints that may hold back a health informatics project. It is poorer at encompassing the drivers that push forward such projects, yet we know from force-field theory that a full understanding of change must take in both drivers as well as constraints [77]. Case experience suggests, not surprisingly, that a project in which there are strong drivers - such as a strong political imperative from outside forces like politicians in central government - can overcome greater constraints (i.e. larger design — reality gaps) than a project in which the drivers are weak (e.g. [76]).

Nonetheless, the design — reality gap model provides a way of standing above the specificities of individual case studies. It offers a generic framework for understanding success and failure, but one which attunes itself to the contingent realities of each particular context. Its main use to date has been as an evaluation tool that explains the outcome of a health informatics project; such as why it failed. But it can also be used as 
a predictive risk assessment tool; identifying key risks and either suggesting or legitimising risk mitigation actions.

Further, and moving from a more static to a more dynamic view of design and reality, the model is part of a slowly-growing body of work that has come to question the notion of planning and control in health information systems development. In practice, rationalist, front-end methodologies seem rather limited in what they can achieve for health IS. They must be set alongside reflections from practice that suggest improvisation has a critical role to play.

From this perspective, both "reality" and "design" are continuously shifting entities, and the process of successfully introducing an HIS can be seen as a set of reciprocating changes to both design and reality that eventually reach some kind of workable closure between the two. In this case, managers, consultants and others involved with HIS introduction should pay less attention to variations on traditional methodology. They should pay more attention to developing the content, tools, roles and competencies that will enable improvised gap closure since this, ultimately, is more likely to deliver the HIS that healthcare users and organisations both need and want.

\section{References}

[1] M. Porta, Is there life after evidence-based medicine?, J. Eval. Clin. Pract. 10 (2004) $147-152$.

[2] W. Tierney, C. McDonald, Testing informatics innovations: the value of negative trials, J. Am. Med. Inform. Assoc. 3 (5) (1996) 358-359. 
[3] C. Sauer, Why Information Systems Fail: A Case Study Approach, Alfred Waller, Henley-on-Thames, 1993.

[4] M.R. Jones, Implementation of an electronic patient record system in a UK hospital, Methods Inf. Med. 42 (2003) 410-415.

[5] R. Roine, A. Ohinmaa, D. Hailey, Assessing telemedicine: a systematic review of the literature, Can. Med. Assoc. J. 165 (2001) 765-771.

[6] I.R. Bowns, G. Rotherham, S. Paisley, Factors associated with success in the implementation of information management and technology in the NHS, Health Inf. J. 5 (1999) 136-145.

[7] C.P. Friedman, J.C. Wyatt, Evaluation Methods in Medical Informatics, SpringerVerlag, New York, 1997.

[8] M.A. Musen, Medical informatics: searching for underlying components, Methods Inf. Med. 41 (2002) 12-19.

[9] R.B. Elson, J.G. Faughnan, D.P. Connelly, An industrial process view of information delivery to support clinical decision making, J. Am. Med. Inform. Assoc. 4 (1997) 266-278.

[10] A. Roesch, H. Gruber, B. Hawelka, H. Hamm, N. Arnold, H. Popal, J. Segerer, M. Landthaler, W. Stolz, Computer assisted learning in medicine: a long-term evaluation of the 'Practical Training Programme Dermatology 2000', Med. Inform. 28 (2003) 147-159.

[11] E. Reussa, M. Menozzia, M. Büchib, J. Koller, H. Krueger, Information access at the point of care: what can we learn for designing a mobile CPR system?, Int. J. Med. Inf. 73 (2004) 363-369. 
[12] C.M. Ruland, A survey about the usefulness of computerized systems to support illness management in clinical practice, Int. J. Med. Inf. 73 (2004) 797-805.

[13] P. Beynon-Davies, M. Lloyd-Williams, Health information systems, 'safety' and organizational learning, Health Inf. J. 4 (1998) 128-137.

[14] H. Laerum, G. Ellingsen, A. Faxvaag, Doctors' use of electronic medical records systems in hospitals: cross sectional survey, Br. Med. J. 323 (2001) 1344-1348.

[15] M. Anderson, Six levels of healthcare IT, in: P.L. Davidson (Ed.), Healthcare Information Systems, Auerbach Publications, Boca Raton, 2000, pp. 97-108.

[16] M. Berg, Implementing information systems in health care organizations: myths and challenges, Int. J. Med. Inf. 64 (2001) 143-156.

[17] D.A. Giuse, K.A. Kuhn, Health information systems challenges: the Heidelberg conference and the future, Int. J. Med. Inf. 69 (2003) 105-114.

[18] N.M. Lorenzi, R.T. Riley, Organizational issues=change, Int. J. Med. Inf. 69 (2003) 197-203.

[19] G. Southon, C. Sauer, K. Dampney, Lessons from a failed information systems initiative, Int. J. Med. Inf. 55 (1999) 33-46.

[20] A. van't Riet, M. Berg, F. Hiddema, K. Sol, Meeting patients' needs with patient information systems, Int. J. Med. Inf. 64 (2001) 1-14.

[21] P.S. Collins, Risk management in information technology projects, in: P.L. Davidson (Ed.), Healthcare Information Systems, Auerbach Publications, Boca Raton, 2000, pp. 209-217. 
[22] N.M. Lorenzi, J.B. Smith, S.R. Conner, T.R. Campion, The success factor profile for clinical computer innovation, in: M. Fieschi, E. Coiera, Y.-C.J. Li (Eds.) Medinfo 2004, IOS Press, Amsterdam, 2004, pp. 1077-1080.

[23] B.P. Bloomfield, The role of information systems in the UK National Health Service, Soc. Stud. Sci. 21 (4) (1991) 701-734.

[24] C. Sauer, Deciding the future for IS failures: not the choice you might think, in: R. Galliers, W.L. Currie (Eds.) Rethinking Management Information Systems, Oxford University Press, Oxford, pp. 279-309.

[25] R. Butler, Designing Organizations, Routledge, New York, 1991.

[26] D.L. Goodhue, R.L. Thompson, Task-technology fit and individual performance, MIS Quart. 19 (2) (1995) 213-236.

[27] I. Zigurs, B.K. Buckland, A theory of task/technology fit and group support systems effectiveness, MIS Quart. 22 (3) (1998) 313-334.

[28] R. Moreton, M. Chester, Transforming the Business: The IT Contribution, McGraw-Hill, London, 1997.

[29] Y.E. Chan, S.L. Huff, D.W. Barclay, D.G. Copeland, Business strategic orientation, information systems strategic orientation, and strategic alignment, Inf. Sys. Res. 8 (2) (1997) 125-150.

[30] P. Beynon-Davies, 'Information systems 'failure': the case of the London Ambulance Service's Computer Aided Despatch project, Euro. J. Inf. Syst., 4 (1995) 171-184. 
[31] K. Lyytinen, R. Hirschheim, Information systems failures: a survey and classification of the empirical literature, Oxf. Surv. Inf. Technol. 4 (1987) 257309.

[32] L. Suchman, Plans and Situated Actions, Cambridge University Press, Cambridge, 1987.

[33] W.E. Bijker, J. Law, General introduction, in: W.E. Bijker, J. Law (Eds.), Shaping Technology/Building Society, MIT Press, Cambridge, 1992, pp. 1-14.

[34] P. Shields, J. Servaes, The impact of the transfer of information technology on development, Inf. Soc. 6 (1989) 47-57.

[35] J. Braa, C. Hedberg, The struggle for district-based health information systems in South Africa, Inf. Soc. 18 (2002) 113-128.

[36] B. Boehm, Software Engineering Economics, Prentice Hall, New York, 1981.

[37] D.E. Forsythe, New bottles, old wine: hidden cultural assumptions in a computerized explanation system for migraine sufferers, Med. Anthropol. Q. 10 (1996) 551-574.

[38] K.C. Laudon, J.P. Laudon, Management Information Systems, $9^{\text {th }}$ edn., PrenticeHall, Upper Saddle River, NJ, 2006.

[39] R.B. Heeks, D. Mundy, A. Salazar, Why Health Care Information Systems Succeed or Fail, $i$ Government Working Paper no.9, IDPM, University of Manchester, UK, 1999.

[40] J. Ballantine, N. Cunningham, Strategic information systems planning: applying private sector frameworks in UK public healthcare, in: R.B. Heeks (Ed.) 
Reinventing Government in the Information Age, Routledge, London, 2001, pp. 293-311.

[41] A. Salazar, Evaluating information systems for decentralisation: health management reform in Ecuador, in: R.B. Heeks (Ed.) Reinventing Government in the Information Age, Routledge, London, 2001, pp. 156-176.

[42] V. Krasnikova, R.B. Heeks, Computerising a Central Asian Epidemiology Service, IDPM, University of Manchester, Manchester, 2003. www.egov4dev.org/epidemiology2.htm [Accessed: 14 Feb 2005]

[43] M.W. Guah, Evaluation and Analysis of Multimedia Information System Design and Implementation at the Coloscopy Unit of St. James University Hospital, Leeds, UK, MSc dissertation, Manchester: School of Management, UMIST, Manchester, 1998.

[44] M.F. Arnold, Tools for planning, in: M.F. Arnold, L.V. Blankenship, J.M. Hess (Eds.) Administering Health Systems, Aldine-Atherton, Chicago, 1971, pp. 250262.

[45] R. Alford, Health Care Politics, University of Chicago Press, Chicago, 1975.

[46] J.G. de Ancos, Societal and professional issues of telematics in healthcare, in: M. Rigby, R. Roberts, M. Thick (Eds.) Taking Health Telematics into the 21st Century, Radcliffe Medical Press, Abingdon, 2000, pp. 101-108.

[47] W.S. Erdley, K. Sackett, R. Pope, Tech versus touch: narrowing the great divide, On-Line J. Nurs. Inf. 7 (2) (2003). www.eaa-knowledge.com/ojni [Accessed: 17 May 2005]

[48] M. Ashmore, M. Mulkay, T. Pinch, Health \& Efficiency, Open University Press, Buckingham, 1990. 
[49] C. Davies, Professionalism and the conundrum of care, in: B. Davey, A. Gray, C. Seale (Eds.) Health and Disease, Open University Press, Buckingham, 1995, pp. 346-351.

[50] G. Dhillon, The Clinical Information System: A Case of Misleading Design Decisions, Case 1-98-IT06, Idea Group Publishing, Hershey, 1998.

[51] C. Scott, Public and Private Roles in Health Care Systems, Open University Press, Buckingham, 2001.

[52] R.B. Heeks, D. Mundy, Information systems and public sector reform in the Third World, in: W. McCourt, M. Minogue (Eds.) The Internationalization of Public Management, Edward Elgar, Cheltenham, 2001, pp. 196-219.

[53] R. Jayasuriya, Managing information systems for health services in a developing country, Int. J. Inf. Manage. 19 (1999) 335-349.

[54] L.O. Silva, J.C. Castro, E.O. Rodriguez, Outsourcing as an improvisation, IFIP WG9.4 Conference on Information Flows, Local Improvisations and Work Practices, Cape Town, 2000.

[55] J.H. van Bemmel, M.A. Musen (Eds.) Handbook of Medical Informatics, Springer-Verlag, Heidelberg, 1997.

[56] S. Tyrell, Using Information and Communication Technology in Healthcare, Radcliffe Medical Press, Oxford, 2002.

[57] J.E.C.M. Aarts, M. Berg, E. Huisman, Health information management education, in: R. Haux, C. Kulikowski (Eds.) Yearbook of Medical Informatics 2003, IMIA, Heidelberg, 2003, pp. 179-183. 
[58] M. Berg, P. Toussaint, The mantra of modeling and the forgotten powers of paper: a sociotechnical view on the development of process-oriented ICT in health care, Int. J. Med. Inf. 69 (2003) 223-234.

[59] H. Mintzberg, The Rise and Fall of Strategic Planning, Prentice-Hall, London, 1994.

[60] W.J. Orlikowski, Improvising organizational transformation over time: a situated change perspective, Inf. Syst. Res. 7 (1996) 63-92.

[61] R.B. Heeks, eGovernment as a carrier of context, J. Public Policy 25 (1) (2005) $51-74$.

[62] C. Ciborra, The Labyrinths of Information, Oxford University Press, Oxford, 2002 .

[63] I. Schramm, V. Weber, Incremental EHR introduction considering the situation in health care and the current standards under development, Int. Congr. Ser. 1230 (2001) 889-894.

[64] R. Lenz, K.A. Kuhn, Towards a continuous evolution and adaptation of information systems in healthcare, Int. J. Med. Inf. 73 (2004) 75-89.

[65] P. Knaup, T. Wiedemann, A. Bachert, U. Creutzig, R. Haux, F. Schilling, Efficiency and safety of chemotherapy plans for children, Artif. Intell. Med. 24 (2002) 229-242.

[66] M. Lettiere, Data warehousing: design through implementation for the healthcare professional, in: P.L. Davidson (Ed.) Healthcare Information Systems, Auerbach Publications, Boca Raton, 2000, pp. 275-289. 
[67] P. Checkland, J. Scholes, Soft Systems Methodology in Action, Wiley, Chichester, 1999.

[68] P.A. Gillis, H. Booth, J.R. Graves, C.S. Fehlauer, J. Soller, Translating traditional principles of system development into a process for designing clinical information systems, Int. J. Technol. Assess. Health Care 10 (1994) 235-248.

[69] S.T. Tang, Y.F. Huang, M.L. Hsiao, S.H. Yang, S.T. Young, Rapid prototyping strategy for a surgical data warehouse, Methods Inf. Med. 42 (2003) 243-250.

[70] M.J. Earl, Management Strategies for Information Technology, Prentice-Hall, Hemel Hempstead, 1989.

[71] J. Aarts, V. Peel, G. Wright, Organizational issues in health informatics, Int. J. Med. Inf. 52 (1998) 235-242.

[72] J.S. Ash, P.Z. Stavri, R. Dykstra, L. Fournier, Implementing computerized physician order entry: the importance of special people, Int. J. Med. Inf. 69 (2003) 235-250.

[73] M.J. Hartswood, R.N. Procter, P. Rouchy, M. Rouncefield, R. Slack, A. Voss, Working IT out in medical practice: IT systems design and development as corealisation, Method Inf. Med. 42 (2003) 392-397.

[74] E.H. van Aulst, H. Springer, The training of the informatics nurse: an intermediary between the discipline of nursing and the developers of information systems, in: R.A. Greenes, H.E. Peterson, D.J. Protti (Eds.) Medinfo '95, Healthcare Computing and Communications Canada, Edmonton, 1995, pp. 13441348 .

[75] G.A. Edwards, R.G. Bushko, Business modeling tools for managing decision support systems, in: R.A. Greenes, H.E. Peterson, D.J. Protti (Eds.) Medinfo '95, 
Healthcare Computing and Communications Canada, Edmonton, 1995, pp. 10051008 .

[76] Y. Chandani, G. Breton, Contraceptive security, information flow and local adaptations: family planning in the Philippines and Morocco, Electronic J. Inf. Syst. Developing Countries 5(3) (2001) 1-18.

[77] K. Lewin, Field Theory in Social Science, D. Cartwright (Ed.), Harper \& Row, New York, 1951. 